\title{
Dysencephalia Splanchnocystica, AKA Meckel-Gruber syndrome: A Systematic Review and the First Case Report from Iraq
}

\author{
Mohammed Hussein Assi ${ }^{1,2}$ \& Ahmed Al-Imam ${ }^{3,4,5,6}$ \\ ${ }^{1}$ Department of Anatomy, College of Medicine, Al-Mustansiriya University, Iraq \\ ${ }^{2}$ Associate Member of the Royal College of Paediatrics and Child Health, United Kingdom \\ ${ }^{3}$ Department of Anatomy and Cellular Biology, College of Medicine, University of Baghdad, Iraq \\ ${ }^{4}$ CERVO Brain Research Centre, Faculty of Medicine, University of Laval, Canada \\ ${ }^{5}$ The Canadian Association for Neuroscience \\ ${ }^{6}$ The Japanese Association of Anatomists
}

Correspondence: Dr Ahmed Al-Imam, Department of Anatomy and Cellular Biology, College of Medicine, University of Baghdad, Bab Al-Mo'adham, 10053, Baghdad, Iraq. E-mail: tesla1452@gmail.com, ahmed.alimam.1@ulaval.ca

Received: December 8, 2018

Accepted: January 2, 2019

Online Published: January 14, 2019

doi: $10.5539 /$ mas.v13n2p149

URL: https://doi.org/10.5539/mas.v13n2p149

\begin{abstract}
Background

Meckel-Gruber syndrome is categorised under the broad "umbrella" of syndromic ciliopathies. There is a shortage of epidemiological studies surveying the region of the Middle East and Arabic countries.
\end{abstract}

\section{Materials and methods}

The review of the literature was conducted systematically, from the $1^{\text {st }}$ to the $9^{\text {th }}$ of June 2018 , across medical and paramedical electronic databases including PubMed-NCBI, the Cochrane Library, and Elsevier database via predefined Medical Subject Headings (MeSH) terms. The words used included all possible combinations of synonyms for Meckel syndrome, Meckel-Gruber syndrome, Gruber syndrome, Dysencephalia Splanchnocystica, ciliopathies, and syndromic ciliopathies.

\section{Results}

The total number of hits for all databases was 2089963 distributed as 2085668 (NCBI-PubMed), 1052 (The Cochrane Library), and 3243 (Elsevier). The most informative combination of keywords was [(Ciliopathies AND "Meckel syndrome type-1"]. The total number of reference material was restricted to twenty-six. The level-ofevidence of our study is level-2b, by the categorisation scheme adopted by the Oxford Centre for Evidence-based Medicine. Our case report represents the first documented case in literature from Iraq. The diagnosis was based on the history of consanguinity of the parents, prior history of induced abortion of a malformed male fetus, and the diagnostic clinical triad postnatally of occipital encephalocele, post-axial polydactyly, and polycystic kidneys manifested as bilateral abdominal distension primarily affecting the loin.

\section{Conclusion}

Future cases from Iraq should be investigated, via ecological and aggregate analytics, in correlation with chemical and radiological exposure following the American invasion of Iraq.

Keywords: Meckel Syndrome type 1, Dysencephalia Splanchnocystica, Ciliary Motility Disorders, Ciliopathies, Arabs, Iraq

\section{Introduction}

Ciliopathies including Meckel-Gruber syndrome (MGS) impose substantial consequences affecting the society and the economy. In the early $19^{\text {th }}$ century, Johann Friedrich Meckel was the first to report cases of this Syndromic Ciliopathy which was later known as "Meckel Syndrome". Nearly one century later, Gruber published similar observations, while applying the term "Dysencephalia Splanchnocystica" (DS) because the condition affects a 
plethora of visceral organs leading to the formation of pathologic encystations (Smith et al., 2006; Lu et al., 2013; Barisic et al., 2015). Meckel-Gruber syndrome is a rare fatal autosomal recessive condition that exists more frequently in populations where high consanguinity occurs (Smith et al., 2006; Baala et al., 2007; Lu et al., 2013; Barisic et al., 2015). The disease is mapped to at least a dozen different chromosomal loci (Table 1) (Smith et al., 2006; Baala et al., 2007; Delous et al., 2007; Tallila, Jakkula, Peltonen, Salonen, \& Kestilä, 2008; Lu et al., 2013; Barisic et al., 2015; U.S National Library of Medicine, 2018).

Table 1. Genes Associated with Meckel Gruber Syndrome (MGS).

\begin{tabular}{ll}
\hline Gene Mutations & Chromosome \\
\hline MKS1 & $17 \mathrm{q} 22$ \\
\hline TMEM216 & $11 \mathrm{q} 13$ \\
\hline TMEM67 & $8 \mathrm{q}$ \\
\hline CEP290 & $12 \mathrm{q}$ \\
\hline RPGRIP1L & $16 \mathrm{q} 12.2$ \\
\hline CC2D2A & $4 \mathrm{p} 15$ \\
\hline NPHP3 & $3 \mathrm{q} 22$ \\
\hline TCTN2 & $12 \mathrm{q} 24.31$ \\
\hline B9D1 & $17 \mathrm{p} 11.2$ \\
\hline B9D2 & $19 \mathrm{q} 13$ \\
\hline TMEM231 & $16 \mathrm{q} 23$ \\
\hline KIF14 & $1 \mathrm{q} 31$ \\
\hline TMEM107 & $17 \mathrm{p} 13$ \\
\hline
\end{tabular}

The triad of polycystic kidneys, occipital encephalocele, and postaxial polydactyly are diagnostic (Smith et al., 2006; Lu et al., 2013; Barisic et al., 2015). However, other associated abnormalities may coexist including Orofacial clefts, genital anomalies and cystic changes in other viscera (Barisic et al., 2015). Failure of the mesodermal induction cascades is incriminated for the pathophysiology of MGS. The cascades occur during early morphogenesis via the orchestrating effect of multiple homeobox genes and growth factors, in addition to the regulation of Hedgehog signalling, ciliary protein localisation and ciliary motility, and ciliogenesis (Dowdle et al., 2011; Abdelhamed et al., 2013; Barisic et al., 2015). The exact prevalence of MGS in the region of the Middle East has not been adequately estimated (Abdelhamed et al., 2013; Barisic et al., 2015). Besides, there are no documented cases in literature from Iraq (Smith et al., 2006; Baala et al., 2007; Delous et al., 2007; Tallila, Jakkula, Peltonen, Salonen, \& Kestilä, 2008; Lu et al., 2013; Barisic et al., 2015; U.S National Library of Medicine, 2018). Prospectively, the digital exploration of trends database, via machine learning algorithms, will make a substantial impact on the epidemiologic studies of this condition (Nasrabadi, 2007; Gašević, Dawson, \& Siemens, 2015; Hay, George, Moyes, \& Brownstein, 2016; Poulin, Thompson, \& Bryan, 2016; Steele \& Chandler, 2016; Witten, Frank, Hall, \& Pal, 2016; Al-Imam \& Assi, 2018).

\section{Materials and Methods}

The review of the literature was conducted systematically, from the $1^{\text {st }}$ to the $9^{\text {th }}$ of June 2018 , across medical and paramedical electronic databases including PubMed-NCBI, the Cochrane Library, and Elsevier database via predefined Medical Subject Headings (MeSH) terms. The terms used included all possible synonyms for Meckel syndrome, Meckel-Gruber syndrome, Gruber syndrome, Dysencephalia Splanchnocystica, ciliopathies, and syndromic ciliopathies. Those words were also used in combination with Boolean operators (AND, OR, NOT) as well as parenthesis and quotations. The inclusion criteria included studies with free full-text written in English or Arabic language, studies and reports on humans only, including all levels of the hierarchy of evidence-based medical studies from case reports to systematic reviews, and published in the last five to fifteen years.

\section{Results}

The total number of hits for all databases was 2089963 distributed as 2085668 (NCBI-PubMed), 1052 (The Cochrane Library), and 3243 (Elsevier). The most informative combination of keywords was (Ciliopathies AND 
"Meckel syndrome type 1") which generated 63 hits via NCBI-PubMed only (Table 2). Duplicate articles were eliminated, and all filtered manuscripts successfully that passed the exclusion criteria were scanned via CASP critical appraisal tools to assess the validity and reliability of each study to be deemed suitable for inclusion in the review of the literature (Better Value Healthcare Ltd, 2018). Following the application of the inclusion criteria specific to this report, the total number of reference material was restricted to twenty-six. The level-of-evidence of our study is level-2b following the categorisation scheme adopted by the Oxford Centre for Evidence-based Medicine (CEMB) as of May 2016 (Oxford Centre for Evidence-Based Medicine, 2016).

Table 2. Literature Databases and the Number of Hits based on Keywords Search.

\begin{tabular}{lllll}
\hline & \multicolumn{4}{c}{ Number of Hits per Database } \\
\hline Keyword (MeSH terms) & $\begin{array}{l}\text { PubMed- } \\
\text { NCBI }\end{array}$ & $\begin{array}{l}\text { The } \\
\text { Cochrane } \\
\text { Library }\end{array}$ & Elsevier & Total \\
\hline Ciliopathies & 3904 & 4 & 12 & 3920 \\
\hline Meckel syndrome type 1 & 63 & 0 & 14 & 77 \\
\hline "Meckel syndrome type 1" & 63 & 0 & 14 & 77 \\
\hline Case Reports & 1913551 & 999 & 2250 & 1916800 \\
\hline Evidence-Based Medicine & 156143 & 48 & 872 & 157063 \\
\hline Iraq & 11818 & 1 & 81 & 11900 \\
\hline $\begin{array}{l}\text { (Ciliopathies AND Meckel syndrome type 1) } \\
\text { (Ciliopathies AND "Meckel syndrome type 1") }\end{array}$ & 63 & 0 & 0 & 63 \\
\hline $\begin{array}{l}\text { (Ciliopathies AND "Meckel syndrome type 1" AND Iraq) } \\
\text { (Ciliopathies AND "Meckel syndrome type 1" AND Iraq }\end{array}$ & 0 & 0 & 0 & 63 \\
AND Evidence-Based Medicine) & 0 & 0 & 0 & 0 \\
\hline $\begin{array}{l}\text { (Ciliopathies AND "Meckel syndrome type 1" AND Iraq } \\
\text { AND "Evidence-Based Medicine") }\end{array}$ & 0 & 0 & 0 & 0 \\
\hline $\begin{array}{l}\text { (Ciliopathies AND "Meckel syndrome type 1" AND Iraq } \\
\text { AND Case Reports) }\end{array}$ & 0 & 0 & 0 & 0 \\
\hline $\begin{array}{l}\text { (Ciliopathies AND "Meckel syndrome type 1" AND Iraq } \\
\text { AND "Case Reports") }\end{array}$ & 0 & 0 & 0 & 0 \\
\hline Total Number of Hits & 2085668 & 1052 & 3243 & 2089963 \\
\hline
\end{tabular}

\section{Discussion}

\subsection{Discussion of Literature}

The combinatory prevalence of cystic renal diseases and associated ciliopathies is estimated to be approximately 1:2000 (Kagan, Dufke, \& Gembruch, 2017). The global incidence of Meckel-Gruber syndrome is around 1:140,000 live births while being higher in the Finnish ethnicities (1:9000), the frequency is also towering among Belgians and Bedouins Kuwaitis and being the highest among Gujarati Indians (1:1,300) (Shetty, Alva, Patil, \& Shetty, 2012; Parelkar et al., 2013). The syndrome affects individuals from all ethnic backgrounds with an almost equal male-to-female ratio which is consistent with the autosomal recessive pattern of inheritance (Parelkar et al., 2013; Al-Belushi et al., 2016).

Due to the rarity of the disease, there is a lack of representative inferential data concerning other ethnicities including those from the Middle East. MGS does also exist in Arabs inhabiting the northeast of Israeli-occupied territories in Palestine, while the incidence among Israeli Jews is even higher than the worldwide average (1: 50,000) (Shetty, Alva, Patil, \& Shetty, 2012; Parelkar et al., 2013; Aalimi et al., 2015; Al-Belushi et al., 2016). Further, genomic analysis of MGS in Arabs revealed marked genetic heterogeneity and displayed novel candidate genes, while in the state of Qatar the incidence (2:1000 live births) in the local population is analogous to reports from communities where consanguinity is remarkably high (above 40\%) (Al-Belushi et al., 2016). Barisic and colleagues, via analysis of data accessed via the European Surveillance of Congenital Anomalies (EUROCAT) network, inferred that the prevalence of the syndrome (2.6: 100,000 live births) was stable over time although regional differences within Europe were still observed (Barisic et al., 2015).

Our report will be of high value to medical and paramedical professionals as it represents the first documented case of Meckel-Gruber syndrome from Iraq. Meckel syndrome is one of the catastrophic syndromic ciliopathies. 
The condition is transmitted genetically from parents via an autosomal recessive pattern of inheritance (Figure 1A). The syndrome is not only rare, but it tends to occur at higher rates in populations where high consanguinity exists as in the case of the developing countries of South America, Africa, Middle and the Far East. Though our case scenario could not be linked to potential mutagenesis due to chemical or radiation exposure following the American invasion of Iraq (the post-Saddam era), future studies should explore ecological and aggregate analyses to (dis) prove this theoretical assumption. Accordingly, it is possible that such cases could be seen on the rise in subsequent generations in Iraq, making it a real public health catastrophe and an economic burden on the healthcare system.

\subsection{Case Report}

The study was conducted in compliance with the Ethical approval no. 620-73 on the $15^{\text {th }}$ of May 2016 issued by the authority of the local ethical committee and the Institute Review Board (IRB) of the College of Medicine at the University of Baghdad, Iraq. All patients gave their consent to have their cases reported. This case belongs to the post-Saddam era of Iraq and following the American invasion of Iraq in 2003. It belongs to a middle-class family who are permanent residents inhabiting at Baghdad, the capital city of Iraq. The wife suffered from two incidents of miscarriage (induced abortion). Each abortus was a male fetus while having five healthy daughters as visualised on the pedigree chart (Figure 1B). It is unknown if the family had any history of exposure to radiation or hazardous chemicals. There was neither a history of infection nor an improper maternal medicinal or chemical misuse during pregnancy. The parents, aged about 30 years, are closely related healthy couples (Second-degree relative). They have been married for ten years and have five healthy girls. Five years earlier, they had a planned termination of pregnancy which was of a male fetus with multiple congenital anomalies including occipital encephalocele and bilateral multicystic kidney that was wrongly diagnosed as a case of TORCH infection.

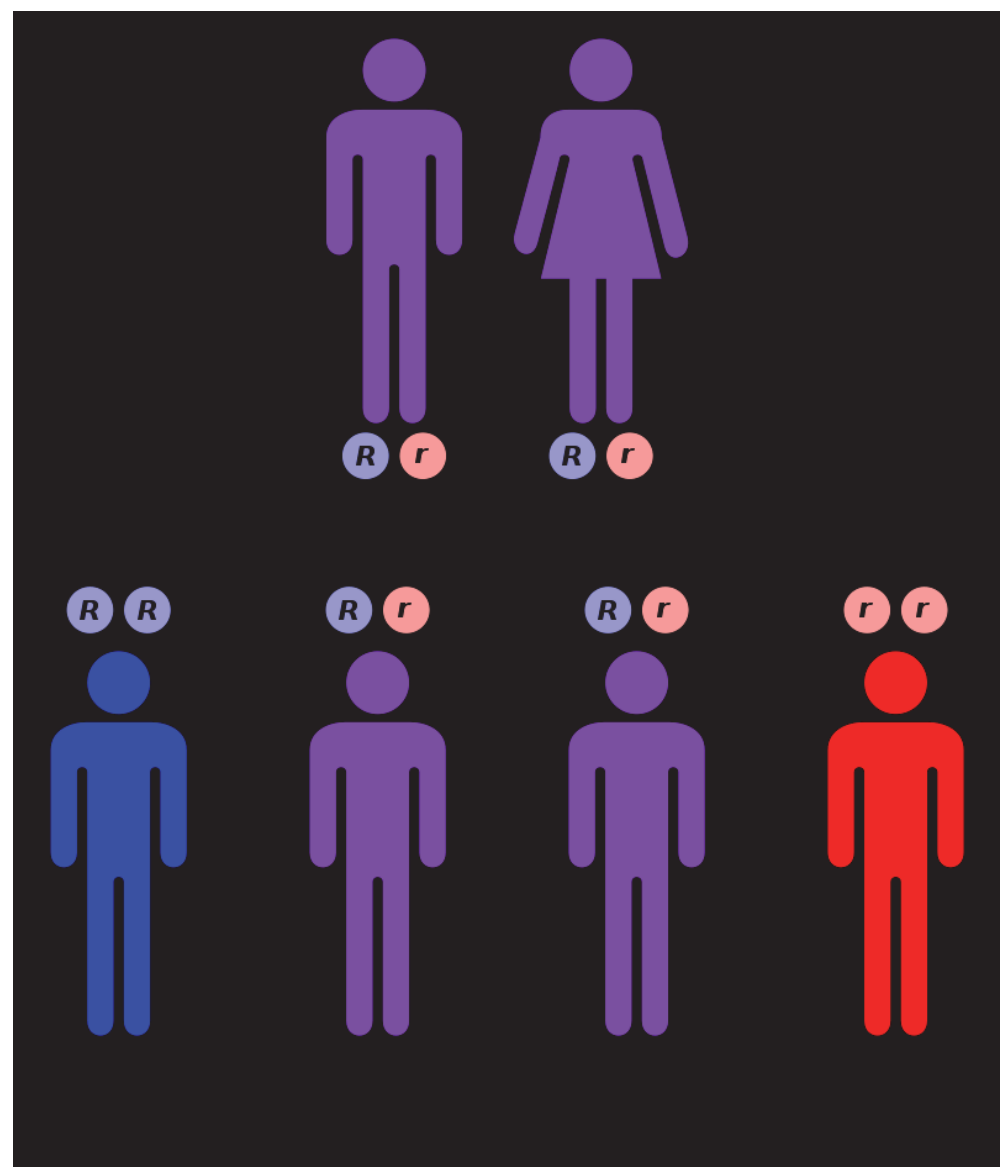

Figure 1A. Schematic Presentation of Recessive Pattern of Inheritance 


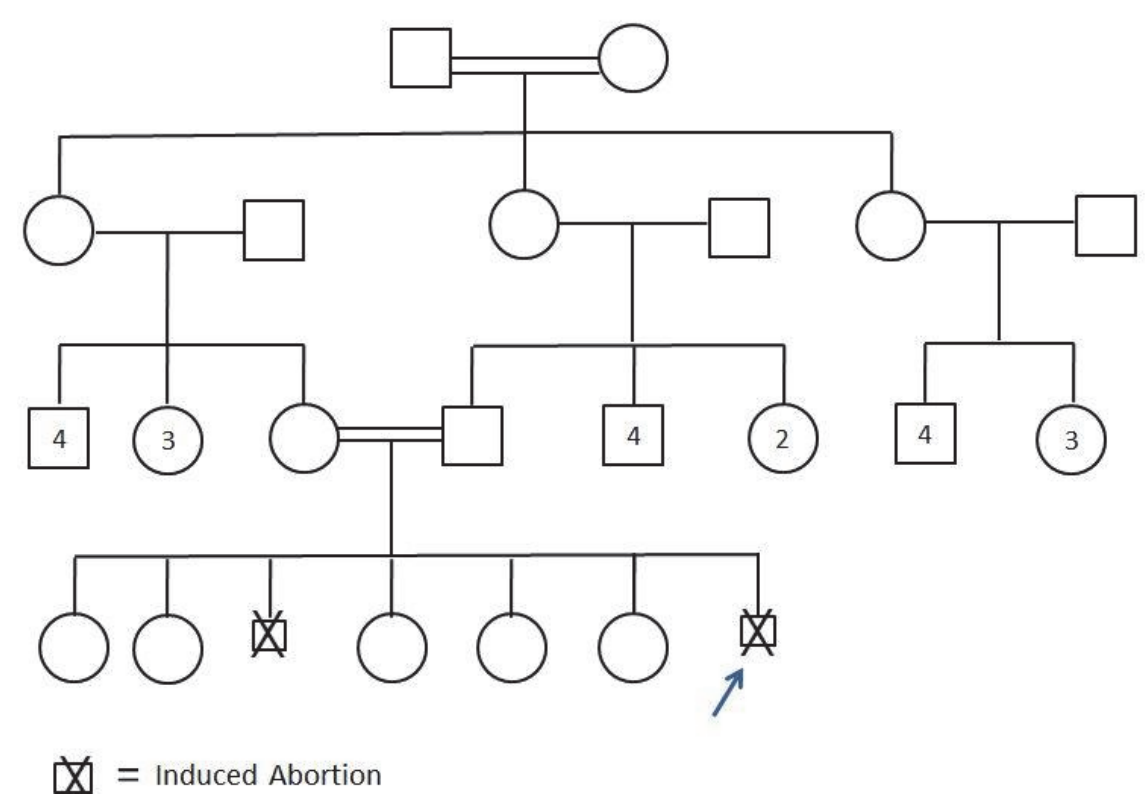

Figure 1B. Pedigree Chart

Recently the wife became pregnant for the seventh time with another male embryo and the family was extremely happy, as they had no male child yet. However, at fourteen weeks of gestation during a prenatal visit, the abdominal ultrasonography confirmed the existence of multiple anomalies affecting the fetus including an occipital encephalocele and bilateral multicystic kidney. According to the ultrasonography, the fetus was estimated to be ageing either 15 or 17 weeks based on fetal length assessment and the biparietal diameters respectively. Fetal body weight was $1600 \mathrm{gm}$ with normal placentation, placental tissue, and amount of amniotic fluid.

However, Doppler ultrasonography of the two umbilical arteries was abnormal. There was a hypoechoic cystic lesion measuring 27 by $30 \mathrm{~mm}$ in diameter affecting the occipital region of the head that was diagnosed as an occipital encephalocele. Both kidneys were enlarged and had multiple small cysts within the renal parenchyma. Based on the prior history of abortion and the ultrasonography report, the parents decided to terminate this pregnancy too. A specialist paediatrician examined the aborted fetus which had a diagnostic clinical triad of Meckel-Gruber syndrome including an occipital Encephalocele, bilateral postaxial polydactyly, as well as an abdominal distention of the loins due to visceromegaly affecting the liver, kidneys, and spleen (Figures 2 and 3). The mother had no anomalies affecting the female genital tract as confirmed by the clinical examination, colposcopy, abdominal ultrasonography and hysterosalpingography. Unfortunately, the parents did not allow conducting any laboratory investigations on the aborted fetus, including taking a fetal biopsy, due to social and cultural restraints. Besides, they had to bury the corpse of the fetus in compliance with the medicolegal regulations of Iraq and the religious standards. Future prenatal counselling and genomic analysis, via next-generation sequencing, were advised to the parents. Besides, online databases of trends, including Google Trends, can provide insight into the digital epidemiology of this condition (Al-Imam, 2018). Such information can be of significant value when combined with real-time and predictive analytics based on machine learning technologies (Al-Imam, 2019; Al-Imam, Khalid, Al-Hadithi, \& Kaouche, 2019). 


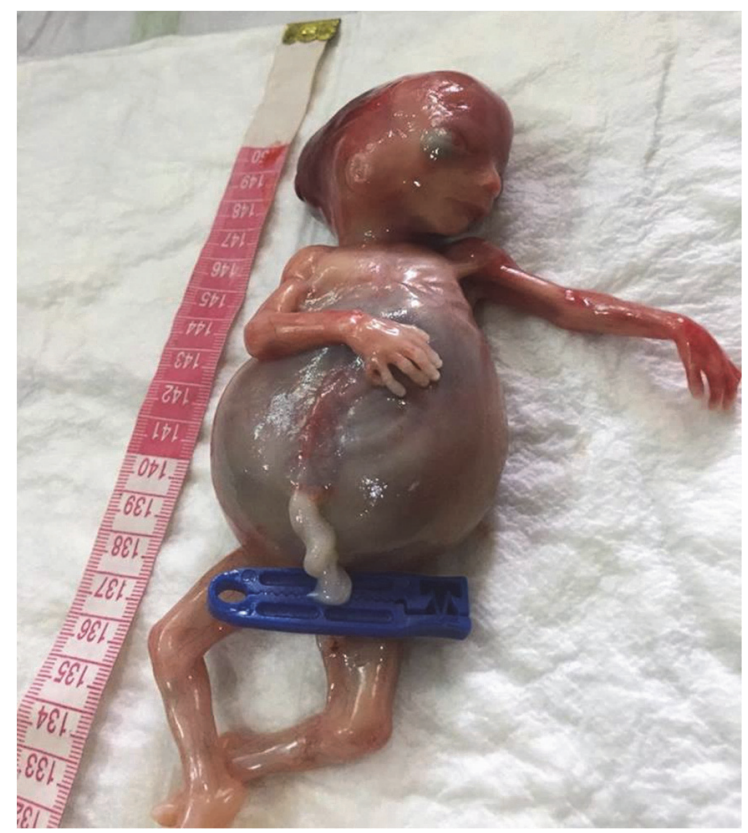

Figure 2. Crown-Heel Length of the Aborted Fetus with Abdominal Distension and Postaxial Polydactyly. $\dagger$ The clinical photograph is approved for publication (consented).

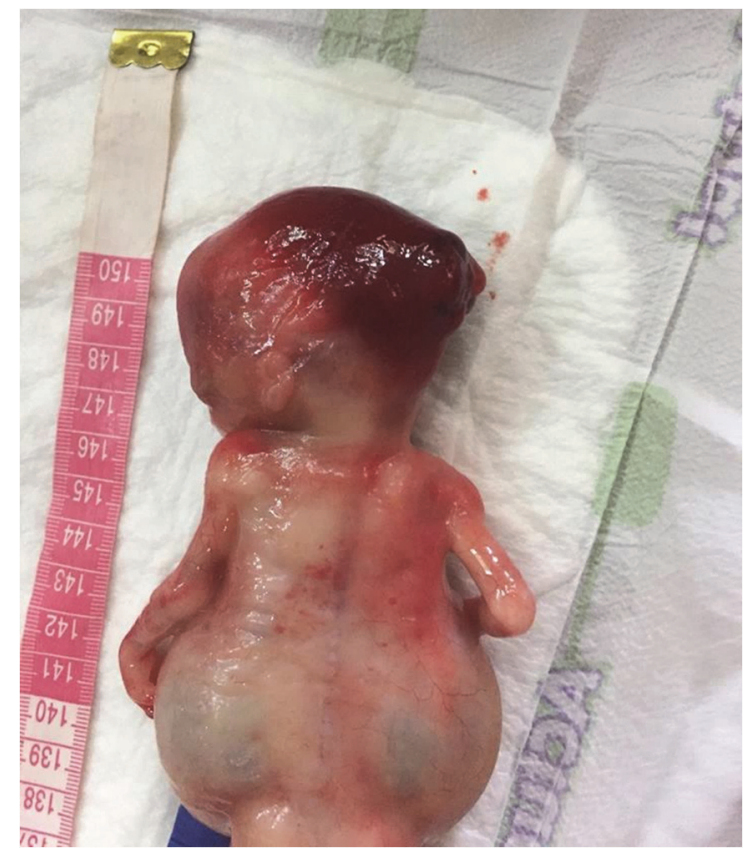

Figure 3. Occipital Encephalocele and Abdominal Distension Most Evident at the Loins (Bilaterally).

$\dagger$ The clinical photograph is approved for publication (consented)

\section{Conclusions}

Our review and case report represents the first documented paper on Meckel syndrome from Iraq. Concerning the case, there was no potential link to radiological and chemical mutagenesis affecting the genome of the parents who are second-degree relatives. The diagnosis was radiologically confirmed prenatally via serial ultrasonography and clinically after abortion via an experienced specialist paediatrician. Genomic analysis via next-generation and whole exome sequencing is mandatory for detailed knowledge of defective genes affecting the DNA of the parents. Trends databases including Google Trends can be consulted in future studies to assess the extent of digital epidemiology and the relevant geographic mapping of this rare condition. Geographic mapping can evaluate the fractional contribution of the Middle East and Arabic countries to the global map. Besides, Google Trends when 
combined with machine learning and data crunching algorithms can extrapolate real-time and predictive analytics of trends. Therefore, it can be integrated into a peremptory warning system to anticipate any change in the interest of surface web users in any rare genetic disease as in the case of Meckel syndrome. The magnitude of benefit of real-time and predictive analytics can be of unique advantage when applied to epidemiological studies via sparing the workforce and financial resources. Future research, via ecological aggregate studies, should also attempt to determine the potential causality of chemical and radiation exposure in inducing genomic instability in this syndrome.

\section{References}

Aalimi, U., Spiegel, E., Chervinsky, I., Attie-Bitach, T., Elkhartoufi, N., Saunier, S., ... Salev, S. (2015). population residing in north-east Israel. Harefuah, 154(10), 632-6.

Abdelhamed, Z. A., Wheway, G., Szymanska, K., Natarajan, S., Toomes, C., Inglehearn, C., \& Johnson, C. A. (2013). Variable expressivity of ciliopathy neurological phenotypes that encompass Meckel-Gruber syndrome and Joubert syndrome is caused by complex de-regulated ciliogenesis, Shh and Wnt signalling defects. Human molecular genetics, 22(7), 1358-1372.

Al-Belushi, M., Al Ibrahim, A., Ahmed, M., Ahmed, B., Khenyab, N., \& Konje, J. C. (2016). A review of MeckelGruber syndrome-incidence and outcome in the state of Qatar. The Journal of Maternal-Fetal \& Neonatal Medicine, 29(12), 2013-2016.

Al-Imam, A. (2018). The digital epidemiology of dysencephalia splanchnocystica, AKA meckel-gruber syndrome: Retrospective analysis and geographic mapping via google trends. Asian Journal of Medical Sciences, 9(5), 81-86.

Al-Imam, A. (2019). A Gateway Towards Machine Learning: Predictive Analytics and Neural Networks in IBMSPSS (SPSS $\quad$ v.24). Retrieved $\quad$ January $\quad 3, \quad 2019$ from https://www.researchgate.net/publication/329029699_A_Gateway_Towards_Machine_Learning_Predictive _Analytics_and_Neural_Networks_in_IBM-SPSS_SPSS_v24. https://doi.org/10.13140/RG.2.2.20885.99041/3

Al-Imam, A., \& Assi, M. H. (2018). Digital Mapping of Genetic Diseases Using Trends Databases: A Retrospective Analysis of Dysencephalia Splanchnocystica AKA Meckel-Gruber Syndrome. In: Proceedings of the 4th International Conference of Iraqi Pediatric Society; 2018 Apr 09; Baghdad (IRAQ). https://doi.org/10.13140/RG.2.2.32762.59840.

Al-Imam, A., Khalid, U., Al-Hadithi, N., \& Kaouche, D. (2019). Real-time Inferential Analytics Based on Online Databases of Trends: A Breakthrough Within the Discipline of Digital Epidemiology of Dentistry and OralMaxillofacial Surgery. Modern Applied Science, 13(2), 81-94.

Baala, L., Audollent, S., Martinovic, J., Ozilou, C., Babron, M. C., Sivanandamoorthy, S., ... Esculpavit, C. (2007). Pleiotropic effects of CEP290 (NPHP6) mutations extend to Meckel syndrome. The American Journal of Human Genetics, 81(1), 170-179.

Barisic, I., Boban, L., Loane, M., Garne, E., Wellesley, D., Calzolari, E., ... Draper, E. S. (2015). Meckel-Gruber Syndrome: a population-based study on prevalence, prenatal diagnosis, clinical features, and survival in Europe. European Journal of Human Genetics, 23(6), 746.

Better Value Healthcare Ltd (BVHC). CASP Checklists. Available at https://casp-uk.net/casp-tools-checklists/ (accessed 20 July 2018).

Delous, M., Baala, L., Salomon, R., Laclef, C., Vierkotten, J., Tory, K., ... Moutkine, I. (2007). The ciliary gene RPGRIP1L is mutated in cerebello-oculo-renal syndrome (Joubert syndrome type B) and Meckel syndrome. Nature genetics, 39(7), 875.

Dowdle, W. E., Robinson, J. F., Kneist, A., Sirerol-Piquer, M. S., Frints, S. G., Corbit, K. C., ... Zerres, K. (2011). Disruption of a ciliary B9 protein complex causes Meckel syndrome. The American Journal of Human Genetics, 89(1), 94-110.

Gašević, D., Dawson, S., \& Siemens, G. (2015). Let's not forget: Learning analytics are about learning. TechTrends, 59(1), 64-71.

Hay, S. I., George, D. B., Moyes, C. L., \& Brownstein, J. S. (2013). Big data opportunities for global infectious disease surveillance. PLoS medicine, 10(4), e1001413.

Kagan, K. O., Dufke, A., \& Gembruch, U. (2017). Renal cystic disease and associated ciliopathies. Current 
Opinion in Obstetrics and Gynecology, 29(2), 85-94.

Lu, Y., Peng, H., Jin, Z., Cheng, J., Wang, S., Ma, M., ... \& Yuan, H. (2013). Preimplantation genetic diagnosis for a Chinese family with autosomal recessive Meckel-Gruber syndrome type 3 (MKS3). PloS one, 8(9), e73245.

Nasrabadi, N. M. (2007). Pattern recognition and machine learning. Journal of electronic imaging, $16(4), 049901$.

Oxford Centre for Evidence-Based Medicine. OCEBM Levels of Evidence. Retrieved July 20, 2018 from https:/www.cebm.net/2016/05/ocebm-levels-of-evidence/

Parelkar, S. V., Kapadnis, S. P., Sanghvi, B. V., Joshi, P. B., Mundada, D., \& Oak, S. N. (2013). Meckel-Gruber syndrome: A rare and lethal anomaly with review of literature. Journal of pediatric neurosciences, 8(2), 154.

Poulin, C., Thompson, P., \& Bryan, C. (2016). Public health surveillance: predictive analytics and big data. In Artificial Intelligence in Behavioral and Mental Health Care (pp. 205-230).

Shetty, B. P., Alva, N., Patil, S., \& Shetty, R. (2012). Meckel-Gruber syndrome (dysencephalia splanchnocystica). J Contemp Dent Pract, 13(5), 713-5.

Smith, U. M., Consugar, M., Tee, L. J., McKee, B. M., Maina, E. N., Whelan, S., ... Aligianis, I. A. (2006). The transmembrane protein meckelin (MKS3) is mutated in Meckel-Gruber syndrome and the wpk rat. Nature genetics, 38(2), 191.

Steele, B., Chandler, J., \& Reddy, S. (2016). Real-time Analytics. In Algorithms for Data Science (pp. 381-401). Springer, Cham.

Tallila, J., Jakkula, E., Peltonen, L., Salonen, R., \& Kestilä, M. (2008). Identification of CC2D2A as a Meckel syndrome gene adds an important piece to the ciliopathy puzzle. The American Journal of Human Genetics, 82(6), 1361-1367.

U.S National Library of medicine. Meckel syndrome. Retrieved May 4, 2018 from https://ghr.nlm.nih.gov/condition/meckel-syndrome\#genes

Witten, I. H., Frank, E., Hall, M. A., \& Pal, C. J. (2016). Data Mining: Practical machine learning tools and techniques. Morgan Kaufmann.

\section{Copyrights}

Copyright for this article is retained by the author(s), with first publication rights granted to the journal.

This is an open-access article distributed under the terms and conditions of the Creative Commons Attribution license (http://creativecommons.org/licenses/by/4.0/). 